\title{
Revisitando o enfoque das epistemologias da política educacional
}

\author{
Revisiting the focus of the epistemologies of \\ education policy
}

\section{Revisitando el enfoque de las epistemologías de la política educativa}

\author{
César Tello* \\ Jefferson Mainardes ${ }^{* *}$
}

\begin{abstract}
Resumo: Nesse artigo, de reflexão teórica, apresentamos uma revisão dos pressupostos anteriormente desenvolvidos sobre o Enfoque das Epistemologias da Política Educacional. Analisamos conceitualmente as categorias centrais que possuem potencialidade analítica para a vigilância epistemológica da investigação no campo e os critérios e a metodologia empregada para o outro uso do enfoque: a metapesquisa. Partindo de uma posição pluralista e de pesquisas anteriores, observamos a necessidade de analisar o campo teórico da política educacional em termos da produção de conhecimento em nossa região. Assumimos que a necessidade de aprofundamento sobre questões teóricas e epistemológicas é um elemento essencial para o fortalecimento das pesquisas desse campo.
\end{abstract}

Palavras-chave: Enfoque das Epistemologias da Política Educacional. Campo teórico. Política Educacional.

\begin{abstract}
This paper presents a review of presuppositions that we had already developed about the focus of education policy epistemologies. The central categories that present analytical potential for the epistemological surveillance of field investigation and the criteria and methodology employed were analyzed for another use of the focus: the meta-research. From a pluralist position and previous research, the need to analyze the theoretical field of education policy in terms of knowledge production in our region was considered. The need to deepen theoretical and epistemological issues was assumed as an essential element to strengthen the research in this area.
\end{abstract}

Keywords: Focus of Education Policy Epistemologies. Theoretical field. Education Policy.

\footnotetext{
" Professor da Universidad Nacional Tres de Febrero, Universidad Nacional San Martin e Universidad Nacional de La Plata. E-mail: <cesargeronimotello@yahoo.com.ar>

${ }^{* *}$ Professor da Universidade Estadual de Ponta Grossa. E-mail: <jefferson.m@uol.com.br>
} 
Resumen: En este artículo, de reflexión teórica, presentamos una revisión de los presupuestos que habíamos desarrollado acerca del Enfoque de las Epistemologías de la Política Educativa. Analizamos conceptualmente las categorías centrales que poseen potencialidad analítica para la vigilancia epistemológica de la investigación en el campo y los criterios y la metodología empleada para el otro uso del enfoque: la meta-investigación. Partiendo de una posición pluralista y de investigaciones previas observamos la necesidad de analizar el campo teórico de la política educacional en términos de la producción de conocimiento en nuestra región. Asumimos que la necesidad de profundización de las cuestiones teóricas y epistemológicas es un elemento esencial para el fortalecimiento de las investigaciones del campo.

Palabras clave: Enfoque de las Epistemologías de la Política educacional. Campo teórico. Política educativa.

\section{Apresentação}

Este artigo possui como eixo central a reflexão e análise teórica, do tipo ensaístico, sobre a análise da produção de conhecimento em política educacional, como campo teórico, que tomou certo impulso em nossa região a partir da criação da Red Latinoamericana de Estudios Epistemológicos en Política Educativa - ReLePe ${ }^{1}$, constituída com o objetivo de promover os estudos teóricos e epistemológicos na pesquisa acadêmica neste campo de estudos.

Desde então, assumimos um posicionamento crítico-analítico e uma perspectiva epistemológica pluralista a partir da qual retomamos algumas ideias e buscamos revisitar aquilo que temos denominado como Enfoque das Epistemologias da Política Educacional (EEPE) e que tem tido certo impacto no campo da pesquisa e produção de conhecimento em política educacional. Este impacto se deu, em vários casos, por ser empregado como um enfoque com potencialidade para a análise de pesquisas (metapesquisa) ou como instrumento de reflexão sobre a própria pesquisa.

Em alguns casos, o EEPE foi tomado como um enfoque prescritivo e demasiado estático em termos dos posicionamentos e perspectivas epistemológicas. Por esta razão e após refletir e seguir estudando a proposta, consideramos ser necessário aclarar algumas questões propostas originalmente e que talvez, não foram explicadas cabalmente nas primeiras publicações. Assim, neste trabalho, revisitamos conceitualmente o EEPE como um espaço de reflexão analítica para a pesquisa em política educacional, a qual situamos entre

\footnotetext{
${ }^{1}<$ http:/ /www.relepe.org $>$
} 
o dogmatismo e o ecletismo epistemológico. Buscamos também pensar e refletir sobre a produção de conhecimento e a dimensão ética, enquanto um elemento chave na constituição do EEPE. Finalmente, apresentamos com maior clareza e a partir de algumas orientações específicas, como desenvolver a metapesquisa no campo da política educacional.

\section{O enfoque das Epistemologias da Política Educacional: entre o dogmatismo e o ecletismo epistemológico}

O enfoque das epistemologias da política educacional (EEPE) é um dos modos possíveis de abordar a análise do campo da pesquisa em política educacional, como explicamos em outro momento (TELLO, 2012; TELLO; MAINARDES, 2012; MAINARDES, 2013; TELLO, 2014). O EEPE pode ser considerado tanto como um enfoque facilitador para o pesquisador em políticas educacionais bem como para desenvolver a pesquisa meta-analítica (metapesquisa) em política educacional (MAINARDES, 2013).

Assim, o primeiro uso enquanto enfoque facilitador se vincula ao exercício da vigilância epistemológica (BOURDIEU; CHAMBOREDON; PASSERON, 2008) sobre os próprios processos de pesquisa, contribuindo para estabelecer e tornar explícito o posicionamento epistemológico do pesquisador em política educacional. A preocupação que impulsionou o desenvolvimento do EEPE teve motivo na mistura desordenada em que se encontravam diversos textos do campo da pesquisa. Essa mistura gerava, conforme Cibulka (1994), pesquisas ateóricas ou, conforme Ball (2006), pesquisas que somente se desenvolvem em uma epistemologia da superfície. Masson (2014), refletindo sobre o EEPE, sugere que "nos resultados de pesquisa na América Latina é muito comum encontrar de forma explícita e com certo desenvolvimento os níveis técnicos e metodológicos de pesquisa: os modos de coleta de informação, a organização técnica, sem observar-se, no entanto, desenvolvimentos teóricos e epistemológicos nas pesquisas".

De algum modo este tipo de pesquisa se encontraria em níveis meramente descritivos, que se desenvolvem de um modo dogmático, ou em seu oposto, com construções teóricas ecléticas. Entendemos que os fundamentos teóricos e epistemológicos de uma pesquisa em política educacional devem permitir a compreensão de um objeto de estudo e não meramente a descrição.

Assim, a perspectiva descritiva presente nas pesquisas nesse campo não permite desenvolver avanços na compreensão, principalmente quando essa perspectiva assume posicionamentos dogmáticos ou ecléticos. Ou, quem sabe, dito de outro modo, os posicionamentos dogmáticos e ecléticos conduzem a pesquisas meramente descricionistas. 
Mainardes (2014), baseado em Dale (2010) e Sayer (1984), propõe três níveis de análise na pesquisa em política educacional, os quais percorrem um caminho desde as descrições até as reflexões teórico-conceituais mais complexas. $\mathrm{O}$ primeiro nível refere-se às pesquisas sobre políticas e programas às quais se vinculam aos "eventos". O segundo nível refere-se às pesquisas de políticas educacionais que objetivam identificar mecanismos, regularidades e a lógica de intervenção (mecanismos). O terceiro nível refere-se às políticas de educação, formado por pesquisas que conseguem apreender os processos e as estruturas, ou seja, os condicionantes mais gerais das políticas. Este último seria o nível de pesquisa de maior profundidade teórica, por meio da criação de conceitos, categorias e explanações teóricas mais desenvolvidas.

Neste sentido, é necessário considerar, seguindo o proposto por Mainardes (2014) que a descrição é parte da pesquisa e não a recusamos per se. Contudo, a dificuldade se estabelece quando não se aprofundam os níveis de pesquisa e a descrição se converte no na perspectiva predominante do processo de pesquisa.

O EEPE é considerado um enfoque que permite estender aos pesquisadores do campo um esquema analítico que se opõe ao modelo ateórico e meramente descritivo da pesquisa em política educacional. Também, neste sentido, argumentamos que o EEPE não deve ser assumido como um instrumento prescritivo para "saber" como se deve realizar pesquisa em política educacional ou, seguindo Masson (2014), tampouco "é uma camisa de força para o pesquisador". Pelo contrário, é um esquema flexível que tenta promover, através de seus componentes, a reflexividade sobre os processos de pesquisa do campo da política educacional buscando maior solidez teórica e epistemológica na pesquisa.

O EEPE se constitui a partir de três componentes: a perspectiva epistemológica, a posição epistemológica e o enfoque epistemetodológico.

Entendemos por perspectiva epistemológica, para o caso das pesquisas em política educacional, a cosmovisão que o pesquisador assume para guiar a sua pesquisa. De algum modo nos referimos ao que Glaser e Strauss (1967) denominam de "teoria geral" vazia" em termos epistemológicos, no entanto existem "cabeças abertas" em busca de resultados de pesquisa. E, neste sentido, Glaser e Strauss (1967), a partir de teoria fundamentada, colocam que não é muito apropriado realizar a análise da realidade tendo a teoria preparada como resposta antecipada do que será encontrado. Isso poderia impedir a geração de uma nova teoria. Mas, certamente a partir da construção subjetiva do pesquisador existem modos de ver a realidade. Neste sentido, Lynch (2001, p. 237) afirma que "os acadêmicos não

${ }^{2}$ Por exemplo: marxismo, neomarxismo, estruturalismo, pós-estruturalismo, pluralismo, etc. 
saem de lealdades paradigmáticas por si mesmos; trabalham com um conjunto de hipóteses que surgem de suas experiências biográficas, linguísticas e culturais únicas".

Distintos autores têm denominado este processo de diferentes modos, por exemplo: conjecturas do pesquisador, antecipação de sentido (SIRVENT, 1999). Na perspectiva anglo-saxã pode-se encontrar como ideias orientadoras que ajudariam a guiar a pesquisa com a categoria de "sensitizing concepts" (conceitos sofisticados), a qual permite, segundo Herbert Blumer, "uma sensação geral de referência" (1954, p. 7). Outros denominam como proposição latente ou pensamentos preditivos (ZEMELMAN, 1998), intuição (OROZCO, 2005), ideias prévias do pesquisador (SABINO, 1996) e pressuposto teórico (WAINERMAN; SAUTU, 2001). Definitivamente "algo existe" previamente à pesquisa. Isso que existe é um pêndulo que se move entre a perspectiva e o posicionamento epistemológico do pesquisador que, como veremos, está inerentemente vinculado ao seu posicionamento ético-político. Uma das maiores dificuldades que nós pesquisadores temos consiste em que nossas estruturas conceituais prévias não possam ser sistematizadas como posicionamentos e perspectivas. Sem dúvida, seguindo os postulados de Glaser e Strauss (1967), deveremos estar abertos aos aspectos que emergirão da realidade que investigamos.

O posicionamento epistemológico deriva da própria perspectiva epistemológica ou deveria resultar em uma pesquisa coerente e consistente. O posicionamento epistemológico, isto é, a teoria substantiva (GLASER; STRAUSS, 1967) vinculada particularmente ao campo de estudos, quer dizer, às correntes teóricas próprias do campo, são aquelas que guardam uma relação direta com o conteúdo empírico e teórico dos dados da pesquisa. Este é o ponto central do EEPE, dado que é aqui onde se põe em jogo a presença da cosmovisão do pesquisador ${ }^{3}$. Entendemos cosmovisão como "um conjunto de pressuposições (ou premissas) que sustentamos acerca da constituição básica de nosso mundo" (SIRE, 2004, p. 17). Isto é, não só os modos de ler a realidade, mas também os modos de construí-la, em termos de reflexividade epistemológica. Neste sentido, o posicionamento epistemológico se converte em posicionamento ético-político do pesquisador, inerente ao seu posicionamento ontológico como o modo de compreender o mundo. No entanto, como nós não nos situamos sobre os modos de compreensão, senão nas formas de construção dessa realidade através do conhecimento científico, é que a denominamos posicionamento epistemológico, como será apresentado mais adiante, sem nos afastarmos da dimensão ontológica.

\footnotetext{
${ }^{3}$ Por exemplo: posicionamento epistemológico crítico-radical, crítico, reformista, neoliberal, institucionalista, reprodutivista, etc.
} 
Por último, o enfoque epistemetodológico é o modo em que se constrói metodologicamente a pesquisa a partir de uma determinada perspectiva epistemológica e de um posicionamento epistemológico. Nenhuma metodologia é neutra, por essa razão, ao explicitar suas bases epistemológicas, o pesquisador deve preocupar-se com a vigilância epistemológica da metodologia de sua pesquisa, cuja construção deve partir da posição e perspectiva epistemológica desenvolvendo construções metodológicas consistentes.

Aqui se faz necessário um esclarecimento, todos temos um posicionamento epistemológico, uma forma de ver o mundo. A questão é até que ponto ou, em outras palavras, o que acontece quando um pesquisador se converte em um pesquisador ortodoxo com características dogmáticas, nas palavras de Meksenas (2008), isto é, um pesquisador que assume um posicionamento epistemológico de um modo que não lhe permite identificar as próprias limitações da perspectiva epistemológica empregada para a indagação de um determinado objeto de estudo. Isto não significa que "vale tudo". É importante assumir o posicionamento, no entanto, pode-se perguntar: até que ponto? até a morte? a intolerância? a impossibilidade de erro na indagação a partir de uma determinada perspectiva epistemológica?

Segundo Meksenas (2008) um pesquisador precisa ter certa predisposição para flexibilizar seu posicionamento epistemológico, quer dizer: sua posição epistemológica não pode ser intransigente porque, em alguns casos, é o próprio objeto de estudo que reclama um modo ou uma outra perspectiva epistemológica para ser indagado, tampouco poderia resguardar-se no ecletismo epistemológico. Isto não implica que não exista um posicionamento epistemológico do pesquisador.

Por vezes, inclusive, se sugere que a política educacional possui um só objeto de estudo, como algo estático. Ball adverte, em termos do campo teórico da política educacional, que:

[...] O significado da política se dá por certo teórica e epistemologicamente integrando-se nas estruturas analíticas que eles constroem. Não é difícil ver que o termo política é utilizado para descrever muitas diferentes 'coisas' em diferentes pontos no mesmo estudo. Para mim, muito se apoia no significado ou possíveis significados que damos à política; isto afeta 'como' pesquisamos e como interpretamos o que encontramos. (BALL, 1994, p. 15).

Assim, a concepção que temos da política educacional gera uma pressuposição sobre a pesquisa em política educacional e, neste sentido, o EEPE propõe a não neutralidade da produção de conhecimentos em política educacional e das diversas construções subjetivas que realiza o pesquisador sobre seu objeto de estudo. Parafraseando Ball (1994), é relevante indagar: o que o pesquisador compreender por política educacional? 
Por tais razões, reafirmamos: a ausência de posicionamento epistemológico explícito pode levar a níveis epistemológicos superficiais, com uma debilidade teórica que pode constituir uma perspectiva meramente descritiva, correndo o risco de assumir o dogmatismo e/ou ecletismo epistemológico.

Assim, o EEPE assume um olhar falibilista, segundo Fávero e Ody (2014, p. 54), uma vez que "as atuais discussões epistemológicas nos levam a questionar, de forma cada vez maior, as posturas extremas acerca do conhecimento”.

Em oposição ao pensamento dogmático e ao ecletismo, se desdobram a partir do EEPE algumas questões-chave em termos analíticos. Boaventura de Sousa Santos afirma em uma entrevista realizada por Manuel Tavares (2007), que:

Sempre afirmei que o pensamento crítico, orientado à transformação social emancipatória, não pode ser relativista. O importante é, pois, não confundir pluralismo epistemológico com relativismo epistemológico. A ecologia dos saberes não é possível sem pluralismo epistemológico, e seria um exercício inútil no contexto do relativismo epistemológico. (TAVARES; SANTOS, 2007, p. 135).

Deste modo existe um limite em qualquer perspectiva epistemológica e posicionamento que se assume. Esse limite está relacionado ao fato de que existem múltiplas verdades nos resultados de pesquisa, entretanto, essas múltiplas verdades surgem desde um posicionamento epistemológico. Neste sentido, Zemelman (1998, p. 1) destaca que "a realidade que enfrentamos, a realidade sócio histórica, possui múltiplos significados. Não se trata de uma realidade clara, inequívoca, com uma significação cristalina e que se possa abordar de modo tão simples". Com isso, torna-se necessário considerar que nos cenários recentes de análise de políticas educacionais as referências de conhecimento estão perdendo claridade e começam a aparecer numerosas linhas de pensamento e que as referências tradicionais de conhecimento, que uma vez foram tidas como estáveis, são questionadas. Um crescente número de autores considera as orientações fundacionais do conhecimento, quer sejam positivistas, interpretativas ou marxistas, como incompletas e problemáticas. Por exemplo, Húsen (1990) admite a incapacidade de um só paradigma para dar respostas a todas as perguntas. Em outras palavras, um paradigma, por definição, exclui aquelas perguntas que considera irrelevantes. Esta situação está configurando um cenário epistemológico caracterizado por uma heterogeneidade emergente (PAULSTON, 1995).

Para Sibeón (2004, p. 27) "a inevitabilidade provável de incertezas e ambiguidades intelectuais complexas que rodeiam tanto o conteúdo da teoria social e a relação dos observadores e pesquisadores sociais com o mundo social é inevitável". Esta situação traz aos pesquisadores de política educacional um grande 
desafio: quais são nossas flexibilidades epistemológicas para desenvolver marcos teóricos que nos permitam compreender a realidade. De que modo estamos pensando o marxismo, o estruturalismo, entre outros, como perspectivas epistemológicas para compreender as realidades político-educacionais?

Toda pesquisa deve enriquecer-se, então, com outras perspectivas de pesquisa que visibilizem novas "zonas de conhecimento possível” (GONZÁLEZ REY, 2002). Claro que, de algum modo, torna-se inalcançável desenvolver uma pesquisa a partir de todas as zonas de conhecimento possíveis. Por isso, é necessário e esclarecedor assumir uma perspectiva e um posicionamento epistemológico para poder dialogar nos limites das verdades. Assim, a partir do EEPE, assumimos que há distintas, conflitivas, mas ao mesmo tempo verdadeiras descrições do mundo que advém dos posicionamentos que assumem os pesquisadores em política educacional.

Seguindo Ball - em uma entrevista a ele realizada por Mainardes e Marcondes (2009) - "todos querem 'conclusões', querem claridade, certeza e fechamento" em termos de uma verdade que tem que a ver com um posicionamento epistemológico. Mas esse tem sido o caminho da pesquisa em política educacional nos últimos 60 anos de pesquisa na América Latina e, poderíamos dizer que não tem havido muitos avanços nos modos de pesquisar e nos resultados obtidos. De fato, na cotidianidade da vida universitária, os professores de política educacional, orientadores de teses e dissertações têm uma grande preocupação pela forma com a qual se investiga no campo.

\section{Por que Epistemologias da política educacional?}

O termo epistemologia, de origem grega, de modo geral, é tomado como sinônimo de teoria do conhecimento, isto é, a teoria da produção de conhecimento. Deste modo, faz referência ao conhecimento metódico e sistemático, isto é, científico. Em termos de Bunge (1981), a epistemologia estuda a pesquisa científica e o conhecimento científico: os modos de produção e difusão do conhecimento. Por esta razão consideramos que "as epistemologias da política educacional" se referem à análise do caráter científico da política educacional como campo teórico. Do mesmo modo, é necessário esclarecer que, em nossa perspectiva, o epistemológico não confronta com a realidade, com a dimensão empírica da vida real, já que os processos científicos são inseparavelmente teoria e realidade, desenvolvimento do conhecimento e processos sociais ${ }^{4}$. A

\footnotetext{
${ }^{4}$ No entanto, cabe esclarecer, por vezes o conhecimento científico desprestigia e deixa de lado a doxa, o conhecimento popular ou os denominados saberes comuns. O desprestígio desse conhecimento não é pilar de nossa definição de epistemologia. Ou seja, consideramos que todo conhecimento deve ter lugar, deve ter "voz", mas existem distintos tipos de conhecimentos, o olhar que desprestigia os saberes populares se posiciona em um positivismo acadêmico do qual queremos nos distanciar. Também, devemos considerar, que
} 
epistemologia que confronta com a realidade empírica não é outra coisa que mera abstração indolente.

Referindo-se ao EEPE, Saviani (2013) explica que:

[...] a expressão epistemologia das políticas educacionais estaria referindose à análise do caráter científico das políticas educacionais. Considerando que a teoria do conhecimento ou gnosiologia tem por objeto o estudo das condições de possibilidade, legitimidade, valor e limites do conhecimento humano, se deduz que a epistemologia tem por objeto o estudo das condições de possibilidade, legitimidade, valor e limites do conhecimento científico. Em consequência, a epistemologia das políticas educacionais apontaria ao estudo das condições de possibilidade, legitimidade, valor e limites do conhecimento científico que se pode produzir sobre as políticas educacionais. (SAVIANI, 2013, p. 497).

Para outros autores, a epistemologia é aquela parte da ciência que tem como objeto (não o único) fazer um percurso pela história do sujeito com respeito à construção do conhecimento científico; isto é, a forma como este objetivou, especializou e outorgou um status de cientificidade ao mesmo; e igualmente, o reconhecimento que goza este tipo de conhecimento por parte da comunidade científica. É aquela epistemologia que estuda a gênese das ciências; que examina de que modo o ser humano tem transformado ou compreendido seu entorno por meio de diversos métodos na necessidade de explicar e compreender fenômenos. Esta última concepção, assumida por Thuillier (citado por MARDONES, 1991), ao considerar a noção de epistemologia como aquela "ciência ou filosofia da ciência que não impõe dogmas aos cientistas, mas que estuda a gênese e a estrutura dos conhecimentos científicos". Para o autor, a epistemologia não é um sistema dogmático conformado por leis imutáveis e impostas; mas, em vez disso, é esse transitar pelo conhecimento científico que se move no imaginário da época; as reflexões sobre o mesmo e o rompimento ou "crise" das normas que sustentam um paradigma em particular e próprio de uma comunidade científica (KUHN, 2001).

Como indicamos em outro momento (TELLO; MAINARDES, 2014) quando um pesquisador não assume uma perspectiva epistemológica convencional, como o marxismo, estruturalismo, etc., muitas vezes é considerado como um pesquisador pós-moderno, igualando o posicionamento pós-moderno ao relativismo epistemológico. Acreditamos que é necessário realizar uma discussão de fundo sobre as perspectivas convencionais e as perspectivas emergentes que

alguns creem que o conhecimento sistemático é mais importante que o conhecimento popular, o qual é para nós um modo errôneo de entender o conhecimento. No entanto, e como vimos dizendo, as epistemologias da política educacional estudam os processos de pesquisa do campo, sem a intenção de negar os diversos tipos de saberes e formas de conhecer. 
nos permitam desenvolver novos ângulos de análise tais como: neomarxismo, pós-estruturalismo, estudos descoloniais, etc. No entanto, neste sentido, Emir Sader (2009) adverte para a crise ideológica que afetou as práticas teóricas e as ciências sociais:

[...] com a desqualificação das chamadas metanarrativas e a utilização generalizada da ideia de crise dos paradigmas. Em consequência disso, foram abandonados os modelos analíticos gerais e aderiu-se ao pós-modernismo, com as consequências indicadas por Perry Anderson: estruturas sem história, história sem sujeito, teorias sem verdade, um verdadeiro suicídio da teoria e de qualquer tentativa de explicação racional do mundo e das relações sociais. (SADER, 2009, p. 117).

Por outro lado, devemos considerar a advertência de Ingrosso, de 35 anos atrás, mas que se converte em uma afirmação atual, segundo o estado do campo que temos descrito:

Nenhum aparato conceitual serviu para apreender a racionalidade e o desenvolvimento dos acontecimentos sociais em nossos países: até há alguns anos, uma década ou pouco mais, as ciências na América Latina encontravam-se em uma situação de quase completa dependência com respeito às norte-americanas e europeias [...]. Copiava-se quase acriticamente fins, interpretações, análises e instrumentos metodológicos das ciências sociais ocidentais, com adaptações de escassa importância à realidade latinoamericana. (INGROSSO, 1973, p. 18).

O EEPE busca contribuir para a reflexão epistemológica da produção de conhecimento em política educacional na América Latina assumindo a multiplicidade de perspectivas epistemológicas, nas palavras de Sousa Santos, das perspectivas epistemológicas que sempre estiveram de 'um lado da linha' (as visíveis) e aquelas que se encontram do 'outro lado da linha' (as não visíveis). (SOUSA SANTOS, 2009, p. 31).

O EEPE pode ser compreendido como um "epistemologismo" ou exacerbação hiperbólica da constituição epistemológica. Por esta razão, fazemos nossas as palavras de Nietzsche em nossa concepção epistemológica:

Permanecei fiéis à terra, irmãos, com o poder de vossa virtude! Vosso amor generoso e vosso conhecimento devem servir ao sentido da terra! Vos imploro encarecidamente. Não permitais que levantem voo, e abandonem as coisas terrenas, e com suas asas golpeiem contra paredes eternas! Ai, em todo tempo há havido muita virtude que voando se extraviou! Conduzi, como eu, a virtude extraviada de regresso à terra, de regresso ao corpo e à vida; para que dê à terra seu sentido, um sentido de homens para homens! (NIETZSCHE, 2000, p. 87). 
Considerando que para cada epistemologia há um posicionamento ético correspondente, assumimos o EEPE como um desafio (no sentido de Gewirtz), que consiste em levar a cabo uma "reflexividade ética sobre o trabalho de pesquisa” (GEWIRTZ, 2007, p. 7), para construir sentidos sobre a realidade, sentidos da terra, sentidos de homens para homens.

Uma última consideração dessa seção refere-se à denominação de "epistemologias" e sua distinção com a categoria de "teoria" e "ontologia", que será útil para compreender os componentes do EEPE apresentados em seção anterior.

Sem entrar em análises profundamente filosóficas, definimos aqui as epistemologias da política educacional como aquele esquema analítico que analisa os processos e os modos de produção de conhecimento, enquanto a ontologia se pergunta pelo essencial das coisas, o sentido, a finalidade teleológica. Poderíamos argumentar que a ontologia das políticas educacionais se pergunta pela finalidade das políticas. Blaikie (2000, p. 8) propõe que "existe uma relação entre as suposições ontológicas e epistemológicas. Nossos pontos de vista da realidade tendem a definir nossas posturas epistemológicas".

Por outro lado, a categoria de teoria é empregada como um modo de definir um conjunto de proposições inter-relacionadas que tentam explicar e descrever a realidade. Outro uso muito comum é vinculá-la ao pensamento de um intelectual que deu lugar a uma perspectiva epistemológica. Por exemplo a teoria marxista. Em nossa perspectiva, o marxismo é uma perspectiva epistemológica, dado que nosso objeto de estudo se centra nos processos de construção do conhecimento e as teorias são conclusivas. $O$ pesquisador poderá empregar a teoria marxista, mas aos efeitos do EEPE 'essa teoria' se constrói na medida em que é empregada para a análise de políticas educacionais. Para o EEPE não é conclusiva.

Por outro lado, não denominamos o EEPE como "teoria" porque se constitui em um enfoque analítico sobre a produção teórica dos pesquisadores. A teoria é uma concepção do mundo. Existem as teorias ou correntes teóricas do marxismo, estruturalismo, pós-estruturalismo, pluralismo, etc, no entanto o EEPE se converte em um esquema empregado para pensar essas teorias em desenvolvimento dentro de uma pesquisa em política educacional.

Se há algo que ficou claro no debate epistemológico contemporâneo é que as perspectivas epistemológicas são theory-laden (carregadas de teoria) e, por consequência, value-laden (carregadas de juízos de valor).

Zemelman (2003), ante a situação problemática do posicionamento dos pesquisadores em Ciências Sociais, afirma: 
[...] Sendo assim, quando falamos de pensamento, a que nos referimos? A um pensamento que se entende como uma postura, como uma atitude que cada pessoa é capaz de construir para si mesma frente às circunstancias que quer conhecer [...] Surge então uma discussão interessante que simplesmente me limito a apontar: a necessidade de distinguir entre um pensamento teórico e um pensamento epistêmico, cuja diferença está precisamente em como se resolve a relação do pensamento com essa realidade que se quer nomear. (ZEMELMAN, 2003, p. 7).

Nesse sentido, as categorias podem ser possibilidades de conteúdo, mas não são conteúdos demarcados, perfeitamente identificáveis com uma significação clara, unívoca. As categorias devem ter sustentação. Na pesquisa em políticas educacionais, essa sustentação é epistemológica e deve possuir certa rigorosidade. No entanto, não nos referimos à rigorosidade que aprisiona ou cerceia a possibilidade de conhecer, mas sim à rigorosidade da coerência.

Bracken (2010) ao distinguir a questão epistemológica e ontológica em pesquisa toma como referência o dicionário Stanford de Filosofia (2009) e explica que "a epistemologia trata sobre os problemas que têm que ver com a criação e difusão do conhecimento em áreas particulares da pesquisa” (BRACKEN, 2010, p. 3).

Por esta razão, temos denominamos o enfoque como EEPE, uma vez que propomos a análise da produção, criação e difusão do conhecimento no campo específico.

Isto não significa que o EEPE desconheça outros componentes-chave e, neste sentido, e coincidindo com Masson (2014), o EPEE deve buscar "articular elementos lógicos, metodológicos, teóricos, epistemológicos e ontológicos" para fins de análise da própria pesquisa ou para o desenvolvimento de metapesquisa.

\section{Produção de conhecimentos em política educacional e reflexividade ética}

Em primeiro lugar, consideramos que a pergunta pela produção de conhecimento em política educacional é precisamente uma pergunta política. Neste sentido, Lynch (2001, p. 240) expressa uma preocupação com o "relativo silêncio" sobre os valores na pesquisa. O EEPE assume em sua centralidade, em seu núcleo, como uma epistemologia dos valores éticos. Lynch argumenta que a maioria das pesquisas assume um "domínio normativo positivista ou pósmoderno [...] ainda que isto permaneça implícito” (LYNCH, 2001, p. 240). E explica que estas são apenas crenças subteóricas, que se interiorizam, como dissemos anteriormente, de um modo subjetivo e, assim: 
Crenças subteóricas se convertem com frequência em silêncios e ausência nas análises acadêmicas [...]. Há limites à autorreflexão; muitos dos valores e suposições que sustentamos mais intimamente são os que menos probabilidades têm de ser submetidos à reflexão crítica (LYNCH, 2001, p. 237).

Poderíamos considerar, segundo a argumentação que vimos construindo: dogmático ou eclético, onde a pesquisa se converte em mera descrição e que, algumas vezes, se traduz em ausência de posicionamento. Nas palavras de Singh, Heimans e Glasswell (2014, p. 829)

Há um silenciamento da posição epistemológica (Tello e Mainardes 2012) nisto - uma quietude metodológica que é frequentemente pela referência a um procedimento analítico (por exemplo: dispositivo heurístico, caixa de ferramentas de contexto ou algum outro método organizadamente marcado) que é tanto desvinculado dos recursos teóricos invocados bem como dos resultados que possam ser produzidos.

Neste sentido devemos considerar que somente o "acontecer original da significação" (LÉVINAS, 1980, p. 181), em nossa perspectiva, é digno de ser pesquisado, pois o restante é mera descrição com um silêncio de valores. Para Singh, Heimans e Glasswell (2014, p. 832) isto é altamente arriscado, dado que existe a necessidade de encontrar "novos modos de ver a política educacional e fazer a pesquisa de um modo diferente" já que se perdemos a visão da tarefa filosófica e científica de refletir sore como vemos as coisas e como vê-las de forma diferente.

Desse modo, pode-se obter uma produção de conhecimento individualista, capitalista e "producionista", onde o sentido do "outro" e a reflexividade ética da pesquisa podem ou não estar presentes e enunciadas.

Assim, a intervenção se reinscreve à medida em que a pergunta política possa escrever novos relatos com outros, onde novamente o outro se apresenta como lugar de legitimidade na realidade social latino-americana. De algum modo poderíamos pensar a justiça em termos das ausências. Quem são os ausentes em nossas pesquisas? Acaso as agendas de pesquisa em nossos âmbitos acadêmicos não provêm de uma lista de temas "que estão na moda"?

\section{O Enfoque das Epistemologias da Política Educacional como metapesquisa}

A partir dos componentes analíticos do EEPE, Mainardes (2013) desenvolveu um esquema analítico para a análise de relatórios de pesquisa de política educacional (meta-análise ou metapesquisa). 
Empregamos o termo de metapesquisa, uma vez que o termo de metaanálise ${ }^{5}$ pode ser confundido com o enfoque systematic review proveniente do enfoque baseado em evidência, empregado inicialmente nas ciências médicas e que em políticas educacionais é conhecido pela sigla EPBE (Enfoque das políticas baseadas em evidência). A categoria meta-análise é também empregada em estatística para sintetizar dados de grande magnitude. $\mathrm{O}$ termo meta-análise foi cunhado por Gene V. Glass (1976) dentro dos estudos estatísticos desde a década de 1930. Na atualidade, o termo é empregado para as pesquisas que têm uma preocupação particular por realizar sínteses estatísticas. Neste sentido, a meta-análise se concentra sobre os resultados de pesquisa, e é esse o elemento chave que se tenta sintetizar. Em contraste, a metapesquisa que empregamos é uma técnica qualitativa que busca observar analiticamente o processo de pesquisa presente em artigos, livros, teses, dissertações, etc, em termos de análise de conteúdo. Por esta razão, possui um enfoque centrado na análise interpretativa para compreender, por exemplo, em uma temática determinada, quais são os principais referentes teóricos, marcos teóricos e enfoques empregados nesse conjunto de produções acadêmicas, em nosso caso, em política educacional.

\section{Algumas considerações preliminares sobre a metapesquisa e a análise textual do conteúdo}

Neste gênero de pesquisa podem existir certas reflexões acusatórias de "classificacionistas". Com base em Bourdieu e Wacquant (2005, p. 184), consideramos que toda tipologia cristaliza uma situação e tende a ser arbitrária, na medida em que inclui e descarta os casos que se encontram na fronteira, ou seja, os casos que não se distinguem claramente. Assim, os pesquisadores que se dedicam à metapesquisa devem estar conscientes de tal situação. Por isso, é necessário identificar tendências epistemológicas mais gerais e recorrer a caracterizações mais amplas.

Aqui também é necessário observar que naquelas pesquisas que consideramos como meramente descritivas há um alto nível de classificação, em muitos casos, encoberto. As pesquisas, em suas distintas versões e metodologias utilizam-se de classificações porque em seus procedimentos mais básicos de interpretar e descrever, ao não existir neutralidade, emprega-se a classificação e classifica-se porque se interpreta e descreve de um modo e não de outro.

A análise do discurso como método de análise tem sido muitas vezes recusada na pesquisa em ciências da educação e, em particular, em política educacional e criticada como abstrata ou de pouca rigorosidade científica,

\footnotetext{
${ }^{5}$ Agradecemos o comentário de Jorge Gorostiaga que contribuiu para a reflexão desta categoria para sua correta interpretação.
} 
particularmente frente às pesquisas de carácter quantitativista ou de análise jurídico-institucionalista, indicando que o discurso não possui relevância teórica como objeto de estudo ou que pertence às perspectivas brandas de análise.

Deve-se considerar que em metodologias como as que propomos existe um alto nível de interpretação por parte do pesquisador, dado que as metodologias de análise do discurso, em suas diversas vertentes, buscam interpretar aquilo que não foi dito de um modo explícito.

Neste sentido assumimos a posição de Paulston (1993, p. 133) que emprega a ideia de texto de Barthes (1979, p. 49): “esse espaço social que não deixa linguagem alguma a salvo nem intacta, que não permita a nenhum sujeito enunciador ocupar o lugar do juiz, ou professor, ou confessor ou psicanalista”. Assim, Rolland Paulston assume leituras de sentidos múltiplos dos textos, de acordo com Barthes (1990, p. 254):

[...] Interpretar um texto não é determinar suas características representativas ou referenciais; não é nem sequer um sentido, senão observar a pluralidade em si de seus sentidos, de sua linguagem, seu permanente "mise en abyme": observar que, em última instancia, o texto é uma galáxia de significantes, não uma estrutura de significados.

A metodologia da análise textual de conteúdo na metapesquisa implica uma série de procedimentos, como os que mais apresentaremos posteriormente, que permitam a identificação/construção das diversas visões, às que denominamos perspectivas epistemológicas e posicionamentos, assim também como seus enfoques epistemetodológicos no campo da política educacional. Isto se realiza com a metodologia de análise textual de conteúdo na qual a partir deste enfoque interpretativista se tenta revelar e compreender tanto o conteúdo manifesto como o conteúdo latente dos textos analisados, (BARDIN, 1996; KRIPPENDORFF, 1990; MAYRING, 2000). Assim, a técnica qualitativa da análise textual do conteúdo se converte em procedimento para a interpretação dos artigos, considerando que:

A análise qualitativa de conteúdo se define a si mesma dentro deste marco de trabalho como uma aproximação empírica, de análise metodologicamente controlada de textos ao interior de seus contextos de comunicação, seguindo regras analíticas de conteúdo. (MAYRING, 2000, p. 4).

Para isto, se faz necessário realizar leitura analítica profunda e minuciosa de cada texto (artigo, dissertação, teses, capítulo de livro, etc) para desvelar sua cosmovisão, suas posições de pensamento, postulados de verdade, estratégias de argumentação, com o objetivo de identificar as principais visões, perspectivas epistemológicas e posicionamentos do campo em um determinado período de tempo, região geográfica e/ou temática. Neste sentido, Pérez (1994) propõe que 
o enfoque de análise de conteúdo favorece a obtenção de análises integrais, profundas e interpretativas mais além dos aspectos léxico-gramaticais.

Segundo Cáceres (2003), a análise de conteúdo, como um ramo da análise do discurso ${ }^{6}$, inicia sua aplicação durante a II Guerra Mundial estudando a publicidade no âmbito comunicacional com a intenção de oferecer "a visão mais objetiva possível daquilo que analisava” (CÁCERES, 2003, p. 56). Posteriormente, esta busca metodológica objetivista que tentava responder ao método científico e após diversas críticas (HERNÁNDEZ, 1994), se distanciou das características do monismo metodológico e se desdobrou como análise de conteúdo manifesto e latente. Tesch (1990) se refere a "ramos" analíticos, uma mais orientada ao estrutural (análise do discurso) e outra ao interpretativo (análise do conteúdo). Em termos do desenvolvimento que realizamos em nossas pesquisas consideramos ambas orientações como de complementariedade, considerando o desenvolvimento epistemológico que tem tido a Análise do Discurso a partir de suas vertentes: análise sociossemiótica do discurso político (VERÃO, 1995), análise textual do conteúdo (PAULSTON, 1996), análise política do discurso - APD (LACLAU; MOUFFE, 1987), análise crítica do discurso - ACD (VAN DIJK, 1989), análise psicanalítica-marxista do discurso (ZIZEK, 1992), entre outras.

\section{Dimensões da metapesquisa}

1. Dimensão reflexiva: na metapesquisa, a produção científica do campo da política educacional é tomada como objeto de estudo. O EEPE é uma possibilidade de reflexão da pesquisa do campo, que se constitui como um modo de reflexão e mapeamento do que se está sendo pesquisado, bem como compreender de que modo a pesquisa tem sido realizada e quais são seus principais fundamentos. Alguns exemplos disto podem ser vistos em Tello e Mainardes (2012); Masson e Flach (2014); Souza (2014); Silva e Silva (2014); Arosa (2014); Deitos e Sobzinski (2014); Sossai, Grimm e Loureiro (2014).

2. Dimensão teórico-analítica: as conclusões da metapesquisa podem ser "reinvestidas no trabalho científico" (BOURDIEU, 2011, p. 38)7, bem como podem contribuir para aumentar as possibilidades de cientificidade

\footnotetext{
${ }^{6}$ Tanto a análise textual do conteúdo como a análise do discurso podem abordar os mesmos textos porém as modalidades de trabalho e as descobertas, ainda que similares, determinarão, segundo Valles (2000) ênfases diferentes para os resultados obtidos.

${ }^{7}$ Segundo Bourdieu: "Quando a pesquisa tem por objeto o próprio universo onde ela se realizada, os resul-
tados que procura podem ser reinvestidos imediatamente no trabalho científico a título de instrumento do
conhecimento reflexivo das condiciones e dos limites sociais desse trabalho que é una das armas principais da
vigilância epistemológica. Tal vez só se possa, efetivamente, fazer avançar o conhecimento do campo científi-
co na condição de servir-se da ciência que se possa ter para descobrir e superar os obstáculos que lhe implica à
ciência o fato de ocupar nesse campo uma posição, e uma posição determinada". (BOURDIEU, 2011, p. 38).
} 
da comunidade científica no seu conjunto, enquanto "as possibilidades que cada cientista tem de beneficiar-se com elas em função da posição que ocupa dentro da comunidade científica" (BOURDIEU; CHAMBOREDON; PASSERON, 2008, p. 107).

\section{Contribuiçõos}

De um modo general, consideramos que a metapesquisa no campo da política educacional possui diversas contribuições:

a) permite a ampliação do conhecimento produzido no campo;

b) ajuda na reflexão sobre as possibilidades dos critérios de cientificidade e de vigilância epistemológica e

c) contribui para intensificar o intercâmbio de informação e críticas sobre a produção de conhecimento do campo.

Estes componentes podem contribuir gradualmente para realizar saltos qualitativos na pesquisa do campo, na medida em que a metapesquisa propõe identificar como os pesquisadores do campo estão desenvolvendo suas ideias e proposições, baseando-se em determinados referenciais teóricos e metodológicos. Bourdieu, Chamboredon e Passeron (2008, p. 115) propõem o papel do sistema de controles cruzados é:

Ao confrontar, continuamente, cada cientista com uma explicitação crítica de suas operações científicas e dos pressupostos que implicam, e ao obrigá-lo, por esse motivo, a fazer dessa explicitação o acompanhamento obrigatório de sua prática e da comunicação de suas descobertas, esse "sistema de controles cruzados" tende a constituir e reforçar, incessantemente, em cada um a aptidão para a vigilância epistemológica.

Ainda, para Bourdieu, Chamboredon e Passeron (2008, p. 109), no sistema de controles cruzados, a eficácia da crítica:

depende da forma e estrutura das trocas pelas quais ela se realiza: tudo leva a considerar que a troca generalizada de críticas [...] constitui um modelo mais favorável a uma integração orgânica do meio científico do que, por exemplo, o clube de admiração mútua como troca restrita de serviços ou, o que não é de modo algum mais válido, a troca de polêmicas rituais pelas quais os adversários cumplices consolidam mutuamente os respectivos estatutos. 


\section{O esquema analítico inicial e suas etapas}

\section{1 - Recorte temporal ou temático de análise}

O ponto de partida e a seleção de um conjunto de relatórios de pesquisa (artigos ou outras publicações do campo da política educacional), partindo de um recorte temporal ou temático.

\section{2 - Confecção do registro}

Despois da definição do corpus, se realiza o registro dos artigos em uma planilha combinada, que contém, entre outros dados: referência, resumo, palavras chaves, e todos os dados que possam contribuir para compreender cabalmente os textos de análise.

A seleção se realiza de um modo muito cuidadoso e atendendo as normas metodológicas de universo e amostra. Segundo a quantidade de componentes do universo e amostra, o tempo disponível e os resultados que se deseja obter, poderá optar pela análise do universo ou da amostra.

\section{3 - Leitura sistemática}

O passo seguinte consiste na leitura sistemática dos textos selecionados, empregando o esquema analítico desenvolvido a partir dos fundamentos do EEPE. Este esquema analítico incluiria os seguintes aspectos:

a) tipo de pesquisa (trabalho de campo, documentário, bibliográfica, outra);

b) amplitude do estudo: local, regional, internacional;

c) marco teórico: conceitos chave, fundamentos da pesquisa;

d) técnica e/ou metodologia empregada na pesquisa (procedimentos metodológicos);

e) tipo de abordagem: descritiva, analítica, argumentativa;

f) níveis de abstração: descrição, generalização empírica, criação de categorias/conceitos, teoria (DALE, 2012).

Após a sistematização dos dados gerais da pesquisa, deve-se dar sequência à análise do EEPE para compreender a dimensão profunda dessa pesquisa em termos de perspectiva epistemológica, posicionamento epistemológico e enfoque epistemetodológico. Isto pode ser feito analisando a pesquisa com algumas perguntas: 
- O título supõe a opção por alguma perspectiva epistemológica?

- Quais são os termos chaves? Esses termos supõem a presença de alguma perspectiva?

- Que autores são apresentados na fundamentação teórica do artigo? São autores que pertencem a uma mesma perspectiva epistemológica ou são próximos entre si? Ou não há nenhuma vinculação teórico-epistemológica entre eles?

-Há argumentos explícitos? Quais são esses argumentos? Que autores são usados para desenvolver a argumentação? Dos argumentos centrais se desprendem sub-argumentos?

Após a análise e o percurso pelas perguntas, é necessário considerar:

- A perspectiva epistemológica e o posicionamento epistemológico são explícitos ou há necessidade de uma leitura entrelinhas para defini-lo?

- Quais seriam essa perspectiva e posicionamento epistemológicos?

- Qual é o entrecruzamento que o pesquisador realiza entre os fundamentos teóricos, a metodologia e a análise? Ou seja, é possível observar uma epistemetodologia?

Todos esses aspectos e respostas às perguntas se registram na planilha combinada, o que facilita a análise conceitual. E assim, como passo seguinte, são explorados os tópicos mais relevantes como um conjunto em termos de campo de determinado período de pesquisas ou temática. A identificação dos autores parece não contribuir para a análise, pois o objetivo é analisar em conjunto as reflexões e a solidez teórica e epistemológica das pesquisas selecionadas.

Deve ficar claro que esta metodologia não é acusatória. Ela busca compreender o estado de situação do campo segundo o recorte realizado pelo pesquisador que levará adiante a metapesquisa. O objetivo da metapesquisa não é julgar os trabalhos e seus autores. O objetivo da metapesquisa é compreender como se desenvolvem as pesquisas do campo e a partir de que perspectivas epistemológicas. Assim, a metapesquisa em política educacional possui um amplo espectro de questões que se referem à identificação, por exemplo "a partir de que perspectiva" estão falando os pesquisadores do campo, quais são os seus fundamentos e a favor de que e de quem escrevem, com que propósitos e vínculos.

É necessário destacar que a metapesquisa se diferencia da análise de revisão de literatura (literature review) que, de modo general, busca analisar as principais conclusões de estudos e pesquisas de um tema específico. Embora a meta-pesquisa também organize e sistematize um conjunto de publicações, seu objetivo é analisá-las a partir e dentro de uma perspectiva teórico-epistemológica, isto é: um estudo das bases teóricas do campo. 


\section{Alguns desafios da metapesquisa}

a) $\mathrm{O}$ pesquisador interessado em realizar uma pesquisa meta-analítica necessita ter uma visão de conjunto das perspectivas epistemológicas empregadas no campo, tanto como de outras classificações que são adotadas nas ciências sociais e políticas ${ }^{8}$.

b) É fundamental que o pesquisador meta-analítico compreenda que toda classificação é arbitraria e está vinculada a um propósito. A metapesquisa no campo da produção de conhecimentos em política educacional tem mostrado que muitos pesquisadores não explicitam sua perspectiva epistemológica. Assim, na metapesquisa, o pesquisador necessitará identificar as perspectivas e posicionamentos epistemológicos a partir do marco teórico, os autores empregados, os estilos de análise, etc.

c) A finalidade da pesquisa meta-analítica não é julgar um ou outro trabalho de forma individual ou ao pesquisador, mas sim buscar compreender como o conhecimento vem sendo produzido no campo da política educacional, por um conjunto (ainda que seja de modo parcial) de pesquisadores. Ou seja, de algum modo mostra um estado de situação do campo em determinado período de tempo, região ou temática.

d) A produção no campo teórico é compreendida em sua historicidade seguindo a categoria de episteme da época de Foucault e o campo da política educacional possui ainda poucos estudos da trajetória de pesquisa do campo, ao menos na América Latina. Desde sua institucionalização, por volta de $1950 \mathrm{em}$ alguns países latino-americanos, com impulso na década de 1960 e que completaram esse processo por volta da década de 1970, o campo da política educacional expandiu-se de forma significativa nos últimos anos. Há uma ampla produção de conhecimento no campo. No entanto, ainda são poucas as pesquisas sobre a historicidade da produção de conhecimento em política educacional com o fim de compreender os fundamentos teóricos e epistemológicos.

\footnotetext{
${ }^{8}$ Um exemplo de classificação é a apresentada por Losada e Casas Casas (2010). Segundo esses autores, um enfoque (ou perspectiva teórica) "é um poderosos refletor que nos faz ver certos aspectos da realidade, mas deixa a outros na penumbra ou na total escuridão” (p. 15). A classificação proposta pelos autores inclui os seguintes enfoques:

a) enfoques que privilegiam o interior do ser humano;

b) enfoques que privilegiam o entorno social;

c) enfoques que privilegiam as instituições;

d) enfoques que privilegiam o entorno cultural (construtivista, culturalista, feminista);

e) enfoques que privilegiam o entorno total (estruturalista, sistémico, estrutural-funcionalista, enfoque biopolítico);

f) macromodelo crítico: enfoque marxista ou os enfoques críticos contemporâneos;

g) macromodelo pós-moderno.
} 
e) A coerência e a consistência das pesquisas e publicações necessitam ser analisadas dentro da perspectiva epistemológica empregada pelo autor da pesquisa. Por esta razão o pesquisador que faz metapesquisa deve ter uma mentalidade aberta para a análise.

f) É importante que o pesquisador meta-analítico também expresse os marcos teóricos e princípios éticos que orientam sua própria análise. Por exemplo, conceitos como vigilância epistemológica, sistemas de controles cruzados, rigorosidade científica, podem constituir-se como marcos teóricos para a pesquisa meta-analítica. Aspectos como a importância da análise crítica das políticas, da análise das consequências das políticas para as distintas classes sociais, das relações entre políticas e reprodução social, são exemplos de princípios éticos que podem orientar o trabalho do pesquisador meta-analítico e que poderiam ser explicitados.

g) A identificação do posicionamento epistemológico do pesquisador é uma tarefa altamente complexa e coloca o pesquisador meta-analítico diante de diversas situações. O posicionamento epistemológico (dos autores dos trabalhos investigados) necessita ser compreendido no contexto econômico, histórico, político e social no qual a pesquisa se realizou e no qual o pesquisador está inserido.

\section{Notas finais}

As propostas levantadas neste trabalho formam parte de um desafio que assumimos como parte das reflexões teóricas e epistemológicas que estamos realizando partir do EEPE e que desenhamos como um esquema dinâmico que deve contribuir para evitar tanto o dogmatismo como o ecletismo epistemológico, os quais - como indicamos - levariam a pesquisa por um só caminho: a perspectiva predominantemente descritiva.

Deste modo, as pesquisas que empregam a metapesquisa contribuem para compreender o estado do campo e, portanto, para realizar um diagnóstico acerca de como se produz conhecimento em política educacional. Isto nos permite compreender o estado de situação da pesquisa em política educacional. Seria interminável o trabalho de analisar as pesquisas de toda América Latina, no entanto é possível começar a realizar estes diagnósticos em espaços de menor dimensão: os programas de Pós-Graduação, uma universidade, uma região, etc. O que está claro é que necessitamos ter um diagnóstico, porque muito se fala sobre como pesquisamos, mas poucos são os dados que possuímos.

Isto nos permitirá pensar e refletir sobre o que realmente nos preocupa, a realidade latino-americana, seus desafios, suas políticas, suas escolas, seus professores. 
É necessário que os pesquisadores latino-americanos - sem desconhecer a potencialidade que pode haver em outros países- pensemos nas meninas e meninos de nossa região que ainda não podem ir à escola, nas jovens e nos jovens que abandonam a escola porque devem começar a trabalhar para sustentar a casa. A partir daí, desse caráter, o caráter mais humano da terra, surgem as reflexões teóricas. Porque assim como outros pesquisadores latino-americanos desejamos pesquisas teóricas melhores para melhor compreendermos a realidade e nela poder intervir.

E, deste modo, fica proposto o desafio em busca da compreensão para a transformação de nossa América.

\section{Referências}

AROSA, A. C. Pesquisa sobre política educacional: estudo sobre o GT5 da ANPEd. In: JORNADAS LATINOAMERICANAS DE ESTUDIOS EPISTEMOLÓGICOS EN POLÍTICA EDUCATIVA, 2., 2014. Anais... Curitiba: UFPR, 2014. p. 1-19.

BALL, S. J. Education reform: a critical post-structural approach. Buckingham: Open University Press, 1994.

BALL, S. J. Sociologia das políticas educacionais e pesquisa crítico-social: uma revisão pessoal das políticas educacionais e da pesquisa em política educacional. Currículo sem Fronteiras, v. 6, n. 2, p. 10-32, jul./dez. 2006.

BARDIN, L. Análisis de contenido. Madrid: Akal Ediciones, 1996.

BARTHES, R. From work to test. In: HARIRI, J. (Dir.). Textual strategies: perspectives in post-structuralist criticism. Ithaca: Cornell University Press, 1979. p. 48-63.

BARTHES, R. La aventura semiológica. Barcelona: Paidós, 1990.

BLAIKIE, N. Designing social research. Polity Press: Cambridge, 2000.

BLUMER, H. What is wrong with social theory? American Sociological Review, v. 19, n. 1, p. 3-10, 1954.

BOURDIEU, P. Homo academicus. Florianópolis: Ed. da UFSC, 2011.

BOURDIEU, P.; WACQUANT, L. Una invitación a la sociología reflexiva. Buenos Aires: Siglo XXI, [1992] 2005.

BOURDIEU; CHAMBOREDON; PASSERON. El oficio de sociólogo. Buenos Aires: Siglo XXI, [1973] 2008.

BOWEN, G. A. Grounded theory and sensitizing concepts. International Journal of Qualitative Methods, v. 5, n. 3, p. 1-9, 2006.

BRACKEN, S. Discussing the importance of ontology and epistemology awareness in practitioner research. Worcester Journal of Learning and Teaching, n. 4, p. 1-9, 2010.

BUNGE, M. Epistemología. Barcelona: Ariel, 1981. 
CÁCERES, P. Análisis cualitativo de contenido: una alternativa metodológica alcanzable. Psicoperspectivas - Revista de la escuela de psicología, Facultad de Filosofía y Educación Pontificia Universidad Católica de Valparaíso, v. 2, p. 53-82, 2003.

CIBULKA, J. Policy analysis and the study of the politics of education. Journal of Education Policy, v. 9, n. 5, p. 105-125, 1994. DOI: 10.1080/0268093940090511

DALE, R. A Sociologia da Educação e o Estado após a globalização. Educação \& Sociedade, Campinas, v. 31, n. 113, p. 1099-1120, out./dez. 2010. DOI: 10.1590/S010173302010000400003

DALE, R. Entrevista realizada em 10/12/2012, na Universidade Estadual de Ponta Grossa, Paraná, Brasil, 2012.

DEITOS, J. M.; SOBZINSKI, J. S. Algumas contribuições do materialismo histórico e dialético para a análise de políticas educacionais. In: JORNADAS LATINOAMERICANAS DE ESTUDIOS EPISTEMOLÓGICOS EN POLÍTICA EDUCACIONAL, 2., 2014. Anais... Curitiba: UFPR, 2014. p. 1-23.

FÁVERO, A.; ODY, L. Falibilismo como perspectiva epistemológica en las investigaciones en política educacional. Caracterizando el campo teórico. In: TELLO, C.; ALMEIDA, M. L. P. Los objetos de estudio en política educacional. Hacia una caracterización del campo teórico. Buenos Aires: Editorial Autores Argentinos, 2014.

GEWIRTZ, S. A reflexividade ética na análise de políticas: conceituação e importância. Práxis Educativa, Ponta Grossa, v. 2 , n. 1 , p. 7-12, jan./jun. 2007.

GLASER, B.; STRAUSS, A. The discovery of grounded theory: strategies for qualitative research. Nueva York: Aldine, 1967.

GLASS, G. V. Primary, secondary, and meta-analysis of research. Educational Researcher, v. 10, n. 5, p. 3-8, 1976. DOI: 10.3102/0013189X005010003

GONZÁLEZ REY, F. Sujeto y subjetividad: una aproximación histórico-cultural. México: Thomson, 2002.

HERNÁNDEZ, R. Metodología de la investigación. México: McGraw-Hill, 1994.

HUSÉN, T. Research paradigms in education. In: HUSÉN, T. (Ed.). Education and the global concern. Oxford: Pergamon Press, 1990.

INGROSSO, M. Modelos socioeconómicos de interpretación de la realidad latinoamericana: de Mariátegui a Gunder Frank. Barcelona: Anagrama, 1973.

KRIPPENDORFF, K. Metodología del análisis de contenido. Teoría y Práctica. Barcelona: Paidós Ibérica, 1990.

KUHN, T. La estructura de las revoluciones científicas. México: Fondo de Cultura Económica, 2001.

LACLAU, E.; MOUFFE, C. Hegemonía y estrategia socialista. Hacia una política democrática radical. Madrid: Ed. Siglo XXI, 1987.

LÉVINAS, E. Totalidad e infinito: ensayo sobre la exterioridad. 5. ed. Salamanca: Sigueme, 1980. (Colección Hermeneia). 
LOSADA, R. L.; CASAS CASAS, A. Enfoques para el análisis político: historia, epistemología y perspectivas de la ciencia política. Bogotá: Editorial Pontificia Universidad Javeriana, 2010.

LYNCH, K. Creating a dialogue between Sociological and Egalitarian Theory in Education. International Studies in Sociology of Education, v. 11, n. 3, p. 237-260, 2001. DOI: 10.1080/09620210100200077

MAINARDES, J. Análise epistemológica de políticas educacionais: explorando as contribuições e as possibilidades da meta-análise. In: SIMPÓSIO INTERNACIONAL O ESTADO E AS POLÍTICAS EDUCACIONAIS NO TEMPO PRESENTE, 7., 2013. Anais... Uberlândia: UFU, 2013.

MAINARDES, J. Reflexiones sobre el objeto de estudio de la política educacional. In: TELLO, C.; ALMEIDA, M. L. P. Los objetos de estudio en política educacional. Hacia una caracterización del campo teórico. Buenos Aires: Editorial Autores Argentinos, 2014.

MAINARDES, J.; MARCONDES, M. I. Entrevista com Stephen J. Ball: um diálogo sobre justiça social, pesquisa e política educacional. Educação \& Sociedade, Campinas, v. 30, n. 106, p. 303-318, jan./abr. 2009. DOI: 10.1590/S0101-73302009000100015

MARDONES, J. M. Filosofía de las Ciencias Humanas y Sociales. Materiales para una fundamentación científica. Barcelona: Anthropos, 1991.

MASSON, G. ReLePe: aportes, desafios e contribuições para o campo da política educacional. Conferencia de Apertura. In: JORNADAS LATINOAMERICANAS DE ESTUDIOS EPISTEMOLÓGICOS EN POLÍTICA EDUCACIONAL, 2., 2014. Anais... Curitiba: UFPR, 2014.

MASSON, G.; FLACH, S. O materialismo histórico-dialético nas pesquisas em políticas educacionais. In: JORNADAS LATINOAMERICANAS DE ESTUDIOS EPISTEMOLÓGICOS EN POLÍTICA EDUCACIONAL, 2., 2014. Anais... Curitiba: UFPR, 2014. p. 1-19.

MAYRING, P. Qualitative content analysis. Forum: Qualitative Social Research, v. 1, n. 2, 2000 .

MEKSENAS, P. Ideologia, intelectuais e dogmatismo na ciência. In: BIANCHETTI, L.; MEKSENAS, P. (Eds.). A trama do conhecimento: teoria, método e escrita em ciência e pesquisa. Campinas: Papirus, 2008. p. 57-72.

NIETZSCHE, F. Así hablaba Zaratustra. Longseller: Buenos Aires, 2000.

OROZCO, G. Construcción del objeto de investigación. Revista de Educación y Desarrollo, v. 7, p. 41-50, 2005.

PAULSTON, R. G. Orientaciones de la crisis educacional en América Latina. Un mapa fenomenológico. Revista de educación, Madrid, n. 302, p. 233-256, 1993.

PAULSTON, R. G. Mapping knowledge perspectives in studies of educational change. In: COOKSON, P. W.; SCHNEIDER, B. (Eds.). Transforming schools: trend, dilemmas and prospects. New York: Garland, 1995. p. 137-180.

PAULSTON, R. G. Preface: Four principles for a non-innocent social cartography. In: PAULSTON, R. G. (Comp.). Social Cartography: Mapping Ways of Seeing Social and Educational Change. New York: Garland, 1996. p. 15-24. 
PÉREZ, G. Investigación cualitativa. Retos e interrogantes. Técnicas de análisis de datos. Madrid: La Muralla, 1994.

SABINO, C. El proceso de investigación. Buenos Aires: Lumen Humanitas, 1996.

SADER, E. El Nuevo Topo. Los caminos de la izquierda latinoamericana. Buenos Aires: Siglo XXI Editores, 2009.

SAVIANI, D. Epistemología de las políticas educativas: algunas precisiones conceptuales. In: TELLO, C. (Coord. y Comp.). Epistemologías de la política educacional: posicionamientos, perspectivas y enfoques. Campinas: Mercado de Letras, 2013. p. 495-500.

SAYER, A. Realism and Social Science. London: Sage, 1984.

SIBEON, R. Rethinking social theory. London: Sage, 2004.

SILVA, A. S.; SILVA, C. A. da. Uso da abordagem do ciclo de políticas no Brasil: metodologia ou epistemetodologia? In: JORNADAS LATINOAMERICANAS DE ESTUDIOS EPISTEMOLÓGICOS EN POLÍTICA EDUCACIONAL, 2., 2014. Anais... Curitiba: UFPR, 2014. p. 1-14.

SINGH, P.; HEIMANS, P.; GLASSWELL, K. Policy enactment, context and performativity: ontological politics and researching Australian National Partnership policies. Journal of Education Policy, v. 29, n. 6, p. 826-844, 2014. DOI: 10.1080/02680939.2014.891763

SIRE, J. The universe next door: a basic worldview catalogue. Downers Grove, IL: InterVarsity Press, 2004.

SIRVENT, M. T. Problemática actual de la investigación educacional. Revista del Instituto de Investigaciones en Ciencias de la Educación, Buenos Aires, v. 8, n. 14, p. 64-75, 1999.

SOSSAI, F. C.; GRIMM, V.; LOUREIRO, C. C. Quando o assunto são políticas educacionais e tecnologias da informação e comunicação: um estudo epistemológico sobre os trabalhos publicados nas reuniões anuais da ANPEd na RBPAE (2000-2013). In: JORNADAS LATINOAMERICANAS DE ESTUDIOS EPISTEMOLÓGICOS EN POLÍTICA EDUCACIONAL, 2., 2014. Anais... Curitiba: UFPR, 2014. p. 1-26.

SOUSA SANTOS, B. Una epistemología del sur. La reinvención del conocimiento y la emancipación social. Buenos Aires: CLACSO-Siglo XXI, 2009.

SOUZA, A. R. La investigación en políticas educativas en Brasil: ¿de qué estamos hablando? In: TELLO, C.; ALMEIDA, M. L. P. Los objetos de estudio en política educacional. Hacia una caracterización del campo teórico. Buenos Aires: Editorial Autores Argentinos, 2014.

TAVARES, M.; SANTOS, B. S. Em torno de um novo paradigma sócio-epistemológico. Conversa com Boaventura de Sousa Santos. Revista Lusófona de Educação, Lisboa, n. 10, p. 131-137, 2007.

TELLO, C. Las epistemologías de la política educacional como enfoque y la vigilancia y el posicionamiento epistemológico del investigador. Práxis Educativa, Ponta Grossa, v. 7, n. 1, p. 53-68, jan./jun. 2012. DOI: 10.5212/PraxEduc.v.7i1.0003

TELLO, C.; MAINARDES, J. La posición epistemológica de los investigadores en Política Educacional: debates teóricos en torno a las perspectivas neo-marxista, pluralista y posestructuralista. Archivos Analíticos de Políticas Educativas, v. 20, n. 9, 2012. 
TELLO, C.; MAINARDES, J. El pluralismo como perspectiva epistemológica en la investigación en política educacional. Reflexiones desde el enfoque de las Epistemologías de la política educacional, 2014. Mimeo (inédito).

TESCH, R. Qualitative research: analysis types and software tools. New York: The Falmer Press, 1990.

VALLES, M. Técnicas cualitativas en investigación. Reflexión metodológica y práctica profesional. Madrid: Síntesis Sociología, 2000.

VAN DIJK, T. Social cognition and discourse. In: GILES, H.; ROBINSON, P. (Eds.). Handbook of social psychology and language. Chichester: Wiley, 1989. p. 163-183.

VERÓN, E. Semiosis de lo ideológico y el poder. Buenos Aires: UBA. 1995.

WAINERMAN, C.; SAUTU, R. (Comps.). La trastienda de la investigación. Buenos Aires: Lumiére, 2001.

ZEMELMAN, H. Crítica, epistemología y educación. Revista de Tecnología Educacional, v. 2, n. 13, p. 119-131, 1998.

ZEMELMAN, H. Conocimiento y Ciencias Sociales. Algunas lecciones sobre problemas epistemológicos. México: Universidad de la Ciudad de México, 2003.

ZIZEK, S. El sublime objeto de la ideología. México: Ed. Siglo XXI, 1992.

Recebido em 15/07/2014

Versão corrigida recebida em 10/12/2014

Aceito em 15/12/2014 